\title{
Research on User Adoption of Information Systems
}

\author{
Xin Zhao \\ Graduate School of Management, University of Auckland, Auckland 1010, New Zealand \\ xzha735@aucklanduni.ac.nz
}

Keywords: Information system; User adoption; Information technology

\begin{abstract}
. the information system is built up in a modern way, integrated with people, data and information technology. The successful implementation of information systems is very important to the effectively usage of information system. This paper focused on the adoption of information systems, firstly explained the usage behavior of information system, and then mainly discussed the information technology adoption theory. And the development of information technology adoption theory was further discussed.
\end{abstract}

\section{Introduction}

In the 21st century, the economic globalization and the intense changes of the market has become increasingly obvious. Under the new market circumstances and competition environment, the information technology has become the most important tool of enterprises to keep their position in the fierce market competition. On one hand, the information technology innovation has make revolutionary changes in the way the enterprise survival and development; on the other hand, based on the information system, the enterprise can plan and manage the resources more efficient, and the information system can provide solutions to policy makers to improve work efficiency and comprehensive ability[1]. However, the implementation work of information system has long been regarded as unreliable, costly, error-prone and endeavor[2]. The information system implementation is the focus of enterprise informatization, compared with the informatization construction, the effect of the application and implementation of information system is far from the desired goal. Only when the users use the system properly the expected return of investment can be realized. In other words, the high vacancy rates and low user utilization rate is the direct performance of the failure of information system implementation. Therefore, the effective use of information system on the individual level is the key to the economic growth potential. The information technology can only develop full potential with effective usage, and how to increase the usage rate becomes the main task to solve the problem of the high failure rate of information system implementation.

\section{The usage behavior of information system}

\subsection{Information technology and information system}

In the research field of management, the information system also be called the management information system which is a man-machine system with tacit understanding. The founder of the information system theory Gordon B. Davis thinks that information system is essentially a man-machine system which can provide information and support for enterprise operation and decision-making, including database, computer hardware and software. In the research field of information system, generally, the definition of information technology and information system is universal. The enterprise management information system is the important part of information technology, including OA, CAD/CAM, SCM, CRM, DSS, PM etc. With the development of informatization construction, most of the management software requires complex technology and human resources, and the coordination and cooperation between departments. Therefore, some management software can also be recognized as information system.

\subsection{The usage of information system}

The IT/IS usage behavior is derived from the definition of technology usage in the research of 
technology innovation adoption, and also is the hotspot in management information system research in recent years. The choice, adoption and usage of information system is a gradual process: first is to realize the necessity of the use of information system, then the decision of purchase or investment is needed to make, and most importantly is the training of the end users to familiar with the system. Another term associates with the information system usage is the information system adoption, those two terms are usually regarded as equivalent[3]. The research of usage behavior in the adoption stage based on the theory of reasoned action and the theory of planned behavior have been the hot point of the information system research. In recent years, many researchers use the theory of rational behavior as the basement of the factors influence the usage of information system. More specifically, the adoption of information system is more subjective and stable, focus on the study of the effects of individual psychological feelings, beliefs and attitudes on usage. While information system usage focuses on the results after a kind of decision-making behavior.

\subsection{The performance of user behavior}

In the implementation process of the information system, the specific performance of user behavior hasn't been defined clearly. According to the research about the usage behavior, a concept that closely related and can take example by is the boycott of users. It is generally recognized that the performance of boycott can be divided into three kinds: 1) the aggression. The aggression refers to the aggressive behavior to the individuals who caused problems. 2) the projection. The projection refers to the complaint to the information technology which leads to a difficult work. 3) the avoidance[4]. The avoidance refers to the user behavior of avoiding the information system. What's more, Lapointe and Rivard divided the behavior of boycott into four level: indifference, negative resistance, active resistance and offensive resistance[5].

\section{The information technology adoption theory}

\subsection{The technology acceptance model}

Because of the information technology adoption on individual level is very importance to the implementation of information system on the management level, researchers, led by Davis, gradually realized the organization environmental factors, user psychological factors and the characteristics of the technology itself is very important to information system usage on the individual level. Therefore, a lot of study is focus on driving factors of the information technology adoption intention based on the technology acceptance model (TAM). From the perspective of behavioristics, researchers use the usage behavior as object variable to build different kinds of acceptance model, and carry on the empirical test.

The technology acceptance model (TAM) is a theoretical model to explain the usage technology acceptance based on the theory of rational behavior. The frame of this model is in figure1. Since the TAM model been put forward, it has become the most concise and most influential theoretical model in the field of information system usage behavior research. In TAM model, followed the path that the attitude toward using affects the behavior intention to use, the behavior intention affects the actual system use, and the perceived usefulness and perceived ease of use both have positive effect on the attitude. In the same time, the perceived ease of use has positive effect on the perceived usefulness, and perceived usefulness also has positive effect on the behavioral intention to use.

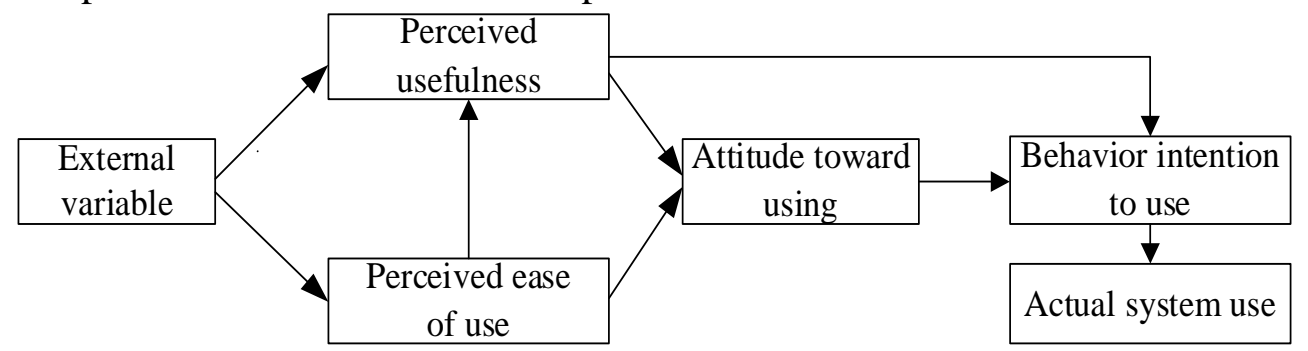

Figure 1 The technology acceptance model

In the research about information technology adoption, the theories in the field of social psychology and behavioral science are widely used for reference, such as the theory of reasoned 
action (TRA), the theory of plan behavior (TPB), the social cognitive theory (SCT) and motivational model (MM) etc. the related theory models of information technology adoption are mostly use the adopt acts of users as the dependent variable of the adoption process to explore the behavior patterns in the process of technology adoption.

\subsection{The influences of technology acceptance model}

The technology acceptance model provides a framework to the information system usage and adoption. Although the TAM model only focus on the determinant of technology acceptance (the perceived usefulness and the perceived ease of use), it did not clarify the formation of the perceived usefulness and the ease of use, but the TAM model provides the basis of the exploring the way the external factors affects the user behavior. Some researchers based on the TAM model try to explore the external factors that affect user cognitive beliefs. In the research about the usage of computer, researchers find that those factors such as the user training, the user computer experience, the system quality, the user computing support and the management support have significant influence on the perceived usefulness and the perceived ease of use.

\section{The development of information technology adoption theory}

Since the TAM model has been put forward, the research of information technology adoption has experienced "theory introduction and validation", "theory of correction" and "different information technology adopted occasions" three stages of development. The construction and demonstration of the integrated theoretical model about information technology adoption deeply improved the depth and breadth of the theoretical research in this field.

\subsection{The focus on the adoption of enterprise information technology}

In view of the enterprise information technology, only about $20 \%$ percent of literature is about the discussion of the user adoption of enterprise information technology. While in the research literatures about the technology adoption, $40 \%$ percent is about the functional information technology adoption, 38\% percent is about the network information technology adoption. With the full penetration of all kinds of information technology in all areas of human economic, social and life, personal technology adoption has become a widely discussed problem. However, compared with the universal application of technology, the application in the production and management of the enterprise information management system has its inherent environmental constraints and value demand. And also because of the high failure rate of the technology application, it is more necessary to strengthen the understanding of individual information system adoption among enterprises.

\subsection{Use individual emotional belief variables to improve the adoption model}

The basis of existing information technology adoption model built from the angle of behavior simply is the theory of rational behavior or planned behavior theory. It only discussed the individual beliefs to the target behavior at the cognitive level, the intention that affect the behavior and the motivation of actual behavior. In fact, the individual behavior also associates with the emotional experience about the expectation and the needs of individuals. The positive emotion can promote individuals to behave more positively in a certain circumstance. However, individual emotional belief variables are not widely used in the existing information system adoption model, and should be extend in future research.

\subsection{Explore the external variables of technology adoption from theoretical perspectives}

With the extension and development of technology adoption theory, the explore about the leading factors of cognitive beliefs such as the perceived usefulness and the perceived ease of use in information technology adoption research can contribute to a more realistic and comprehensive understanding of information technology adoption on the individual level in the organization. In other words, without well understanding of the external factors contribute to the user cognitive, the information system adoption will not be fully promoted. However, the existing research identified a large number of external variables which thought to affect the user cognitive beliefs, there isn't a clear paradigm of the choice of external variables. The choice of the external variables is random and more of a focus on the influence of the user characteristics and technical characteristics to the individual internal adopt. Therefore, it need to explore the external variables of technology adoption 
from theoretical perspectives such as organization structure, cultural values and leadership.

\section{Conclusion}

The understanding of the intension and motive of the usage of information system and the conditions that promote or hinder the system use are mostly decided by the research about the information system adoption. And the research framework of information adoption derives from the research field of the innovation technology adopted theory. Therefore, this study mainly focuses on the technology adoption theory on the individual level. The high vacancy rate of functions and low utilization rate by users are typical signals of setback in information systems implementation, and always lead to great gap between investments and benefits. In the quest of factors influencing user adoption of information system, researchers' views are broadened from user's internal psychological process to external organizational impacts.

\section{References}

[1].Frolick, T.B. and M. N., Erp Implementation Failure: A Case Study. Information Systems Management, 2003. 20(4): p. 43-49.

[2].Yi, M.Y., K.D. Fiedler, and J.S. Park, Understanding the Role of Individual Innovativeness in the Acceptance of IT-Based Innovations: Comparative Analyses of Models and Measures *. Decision Sciences, 2006. 37(3): p. 393-426.

[3].Burton-Jones, A. and D.W. Straub, Reconceptualizing System Usage: An Approach and Empirical Test. Information Systems Research, 2006. 17(3): p. 228-246.

[4].Hirschheim, R. and M. Newman, Information Systems and User Resistance: Theory and Practice. Computer Journal, 1988. 31(5): p. 398-408.

[5].Lapointe, L. and S. Rivard, A Multilevel Model of Resistance to Information Technology Implementation. Mis Quarterly, 2005. 29(3): p. 461-491. 